\title{
Neuropsychiatric symptoms and executive function impairments in Alzheimer's disease and vascular dementia The role of subcortical circuits
}

\author{
Chan Tiel'1,2(1), Felipe Kenji Sudo ${ }^{3}$, Ana Beatriz Calmon ${ }^{1,2}$
}

\begin{abstract}
Neuropsychiatric symptoms (NPS) in dementia are prevalent, under-recognized and little studied regarding their pathophysiological aspects. The pathophysiological mechanism, as well as the possible role of vascular lesions in the genesis of these symptoms, are still matters of debate. Objective: to describe and compare the prevalence and severity of NPS in subjects with Alzheimer's disease (AD) and vascular dementia (VaD). Methods: a cross-sectional study involving 82 outpatients, divided into two groups $(A D \times V a D)$, was conducted. Patients were submitted to the Cambridge Cognitive Test (CAMCOG), the Clock Drawing Test (CLOX 1 and 2), the Neuropsychiatric Inventory (NPI) and the Clinical Dementia Rating (CDR) scale. Neuroimaging was scored using the de Leon and Fazekas scales. Results: $90.8 \%$ of the patients had at least one neuropsychiatric symptom. There were statistical differences on the CLOX test and in the apathy symptoms between $\mathrm{AD}$ and $\mathrm{VaD}$ groups. Apathy and disinhibition proved more prevalent in patients with higher vascular load. Conclusion: apathy and impaired executive function may reflect vascular damage in subcortical circuits in dementia patients.
\end{abstract}

Key words: vascular dementia, Alzheimer, neuropsychiatric symptoms, apathy.

SINTOMAS NEUROPSIQUIÁTRICOS E PREJUIZZOS NA FUNÇÃO EXECUTIVA NA DOENÇA DE ALZHEIMER E DEMÊNCIA VASCULAR: O PAPEL DOS CIRCUITOS SUBCORTICAIS

RESUMO. Sintomas neuropsiquiátricos na demência são prevalentes, pouco reconhecidos e ainda pouco estudados quanto aos aspectos fisiopatológicos. 0 mecanismo fisiopatológico, assim como o possível papel das lesões vasculares na gênese destes sintomas ainda são motivos de debate. Objetivo: descrever e comparar a prevalência e severidade dos sintomas entre a doença de Alzheimer (DA) e demência vascular (DV). Métodos: estudo transversal que incluiu 82 pacientes selecionados, divididos em dois grupos $(\mathrm{DA} \times \mathrm{DV}$ ). Foram submetidos ao teste cognitivo de Cambridge (CAMCOG), teste do desenho do relógio (CLOX 1 e 2), inventário neuropsiquiátrico (INP) e avaliação clínica do estágio da demência (CDR). Avaliação dos índices de neuroimagem foram pelo escore de de Leon e Fazekas. Resultados: 90.8\% dos pacientes apresentavam pelo menos um sintoma neuropsiquiátrico. Houve diferença estatísticas no CLOX e sintoma apatia entre DA e DV. Apatia e desinibição demonstraram ser mais prevalentes nos pacientes com maior carga vascular. Conclusão: Apatia e alteração na função executiva podem refletir danos vasculares nos circuitos subcorticais naqueles pacientes com demência.

Palavras-chave: demência vascular, Alzheimer, sintomas neuropsiquiátricos, apatia.

$\mathrm{D}$ ementia is a syndrome characterized by global acquired cognitive decline, which interferes in patients' activities of daily liv- ing. ${ }^{1,2}$ Although all available diagnostic criteria for this condition have been based on the presence of cognitive impairments, mounting

This study was conducted at the Department of Neurology, Federal University of the State of Rio de Janeiro (UNIRIO), Rio de Janeiro, RJ, Brazil.

${ }^{1}$ Universidade de Vassouras (UV), Medical School, Vassouras, Rio de Janeiro, RJ, Brazil. ²Department of Neurology, Federal University of the State of Rio de Janeiro (UNIRIO), Rio de Janeiro, RJ, Brazil. ${ }^{3}$ Memory Clinic, Instituto D'Or de Ensino e Pesquisa, Rio de Janeiro, RJ, Brazil.

Chan Tiel. Av. Joaquim Leite, 01 / sala 701 - Centro - 27330-040 Barra Mansa RJ - Brazil; . E-mail: chantiel10@hotmail.com

Disclosure: The authors report no conflicts of interest.

Received January 24, 2019. Accepted in final form June 24, 2019.

(c) BY 
evidence recognizes that neuropsychiatric symptoms (NPS) are highly prevalent, ${ }^{3-7}$ highly detrimental to the patient's quality of life and strongly associated with caregiver burden. ${ }^{8-10}$ In addition, NPS may occur independently of the illness stage: in some cases, they may be the most prominent manifestation of the disorder; alternatively, they may precede cognitive changes ${ }^{11}$ or emerge only in moderate/severe stages of the disease.,12 NPS commonly manifest as mood disorders, psychotic syndrome or other frontal features. ${ }^{13}$ More specifically, the most prevalent behavioral and mood symptoms in dementia are apathy, depression, agitation and irritability. ${ }^{3,8,14,15}$

Despite the importance of the issue for clinical practice, data on the pathophysiology of NPS is remarkably divergent or inconclusive in the literature. A cognitive hypothesis for behavioral changes has been formulated, implying that underlying impairments in cognitive functions may be associated with NPS. For instance, apathy may correlate with executive function problems, ${ }^{16}$ whereas a possible relationship between global cognitive impairment and anxiety has been indicated by some authors. ${ }^{17}$ Nonetheless, heterogeneities in the methods used to evaluate these symptoms could account, to some degree, for the disparities in findings across studies. ${ }^{4,5,6,18}$ Notably, the overlap of Alzheimer's disease (AD) and Vascular Dementia (VaD) pathologies in samples may hamper researchers' ability to draw conclusions about the mechanisms underlying these clinical features.

The Neuropsychiatric Inventory (NPI) is possibly the most used instrument to investigate NPS in research and clinical practice. ${ }^{19,20}$ It assesses, through a brief structured interview applied to the patient's caregiver, the frequency and severity of twelve domains of symptoms. ${ }^{19}$ It has been translated into Brazilian Portuguese and validated for the Brazilian elderly population. ${ }^{21}$

The goal of this study was to compare NPI scores in patients with Alzheimer and Vascular disease. We also sought to investigate whether severity of vascular lesions correlated with NPS and cognitive performance in our sample.

\section{METHODS}

\section{Participants}

A cross-sectional study including eighty-two patients with Alzheimer and Vascular dementia, recruited at outpatient healthcare facilities in the state of Rio de Janeiro, Brazil, between May of 2017 and May of 2018 was conducted.

Selection of participants was based on the following eligibility criteria: (1) subjects were diagnosed as presenting $\mathrm{AD}$ or $\mathrm{VaD}$ according to the DSM- 5 criteria (American Psychiatric Association, 2013); (2) individuals were older than 59 years old; (3) subjects agreed to undergo a complete medical investigation, including physical examination, neuroimaging and laboratory tests; and (4) patients had no current or past history of severe psychiatric and neurological disorders, substance abuse, traumatic brain injury or exposure to neurotoxic agents.

\section{Procedures}

Initial assessment of participants comprised a clinical interview and physical evaluation, including neurological examination. Subsequently, a set of cognitive screening tests were applied to the sample: the MiniMental State Examination (MMSE), ${ }^{22}$ Cambridge Cognitive Test (CAMCOG) ${ }^{23}$ and the Clock Drawing Test (CLOX method). ${ }^{24}$ The Clinical Dementia Rating (CDR) scale was employed to determine the staging of cognitive impairment. ${ }^{25}$ The Neuropsychiatric Inventory (NPI) was applied to an informant to measure the presence and severity of NPS. ${ }^{21}$

In addition, brain Magnetic Resonance Imaging (MRI) exams were evaluated if field strengths were at least $1.5 \mathrm{~T}$ and scans had been conducted within 1 year prior to cognitive testing. Severity of white-matter hyperintensities was visually analyzed by a trained neurologist using the modified-Fazekas scale $(\mathrm{mF}){ }^{26}$ Concomitantly, the degree of hippocampal atrophy was rated using the de Leon scale. ${ }^{27}$

\section{Ethics}

The study was approved by the Research Ethics Committee of the Federal University of Rio de Janeiro State (UNIRIO) under the protocol 79326117.1.0000. 5258 .

\section{Data analysis}

The Kolmogorov-Smirnov test was used to measure the normality of data. Mean differences between diagnostic groups ( $\mathrm{AD}$ and $\mathrm{VaD}$ ) were determined using Student's $t$-test for normally distributed continuous variables, while Mann- Whitney's U-test was used in other cases. Pearson's Chi Square was employed to evaluate distributions of categorical variables across groups.

Additionally, subjects were clustered according to $\mathrm{mF}$, and mean differences in continuous variables were analyzed by ANOVA and Tukey's post-hoc test (when variables followed normal distribution) or KruskalWallis test. Partial correlations were used to assess associations among behavioral and cognitive variables 
Table 1. Differences between diagnostic groups for continuous sociodemographic, cognitive and behavioral variables.

\begin{tabular}{|c|c|c|c|c|c|}
\hline Variable & Group & N & Mean & $\begin{array}{l}\text { Standard } \\
\text { deviation }\end{array}$ & p-value \\
\hline \multirow[t]{2}{*}{ Age } & $A D$ & 41 & 76.46 & 7.76 & \multirow{2}{*}{$<0.001^{\star}$} \\
\hline & VD & 41 & 69.48 & 8.55 & \\
\hline \multirow[t]{2}{*}{ Education } & $A D$ & 41 & 5.80 & 3.79 & \multirow{2}{*}{ n.s. ${ }^{*}$} \\
\hline & VD & 41 & 5.19 & 3.28 & \\
\hline \multirow[t]{2}{*}{ CAMCOG } & $A D$ & 41 & 56.58 & 8.31 & \multirow{2}{*}{ n.s. ${ }^{*}$} \\
\hline & VD & 41 & 56.82 & 8.39 & \\
\hline \multirow[t]{2}{*}{ CLOX1 } & $A D$ & 41 & 9.63 & 1.31 & \multirow{2}{*}{$<0.001^{*}$} \\
\hline & VD & 41 & 7.04 & 1.68 & \\
\hline \multirow[t]{2}{*}{ CLOX2 } & $A D$ & 41 & 10.02 & 1.44 & \multirow{2}{*}{$<0.001^{*}$} \\
\hline & VD & 41 & 7.90 & 1.64 & \\
\hline \multirow[t]{2}{*}{ Delusion } & $A D$ & 41 & .17 & .70 & \multirow{2}{*}{ n.s. ${ }^{\star \star}$} \\
\hline & VD & 41 & .75 & 1.71 & \\
\hline \multirow[t]{2}{*}{ Hallucination } & $A D$ & 41 & .82 & 1.98 & \multirow{2}{*}{ n.s. ${ }^{* *}$} \\
\hline & VD & 41 & .73 & 1.44 & \\
\hline \multirow[t]{2}{*}{ Agitation } & $A D$ & 41 & 1.87 & 2.63 & \multirow{2}{*}{ n.s. ${ }^{* \star}$} \\
\hline & VD & 41 & 1.36 & 2.49 & \\
\hline \multirow[t]{2}{*}{ Depression } & $A D$ & 41 & .48 & 1.32 & \multirow{2}{*}{ n.s. ${ }^{*}$} \\
\hline & VD & 41 & 2.82 & 3.47 & \\
\hline \multirow[t]{2}{*}{ Anxiety } & $A D$ & 41 & 1.12 & 1.79 & \multirow{2}{*}{ n.s. ${ }^{\star \star}$} \\
\hline & VD & 41 & 1.04 & 2.60 & \\
\hline \multirow[t]{2}{*}{ Euphoria } & $A D$ & 41 & .29 & 1.05 & \multirow{2}{*}{ n.s. ${ }^{* *}$} \\
\hline & VD & 41 & .04 & .31 & \\
\hline \multirow[t]{2}{*}{ Apathy } & $A D$ & 41 & 1.60 & 2.71 & \multirow{2}{*}{$<0.001^{*}$} \\
\hline & VD & 41 & 4.82 & 3.55 & \\
\hline \multirow[t]{2}{*}{ Disinhibition } & $A D$ & 41 & .19 & .74 & \multirow{2}{*}{ n.s. ${ }^{\star \star}$} \\
\hline & VD & 41 & .26 & .80 & \\
\hline \multirow[t]{2}{*}{ Irritability } & $A D$ & 41 & 1.34 & 2.25 & \multirow{2}{*}{ n.s. ${ }^{* *}$} \\
\hline & VD & 41 & 1.09 & 2.60 & \\
\hline Motor & $A D$ & 41 & .29 & 1.05 & \\
\hline & VD & 41 & .48 & 2.22 & \\
\hline Sleep & $A D$ & 41 & 1.21 & 2.47 & \\
\hline & VD & 41 & 1.07 & 2.32 & \\
\hline Appetite & $A D$ & 41 & .53 & 1.55 & \\
\hline cnange & VD & 41 & .87 & 2.27 & \\
\hline NPI & $A D$ & 41 & 9.97 & 7.55 & \\
\hline & VD & 41 & 15.31 & 13.23 & \\
\hline
\end{tabular}

*Student's t-test; *Mann-Whitney and $\mathrm{mF}$ (analyzed as an ordinal variable), controlling for severity of hippocampal atrophy (as measured by the De Leon scale). Linear Logistic Regression was conducted to verify the predictive relationship of cognitive and behavioral aspects with white-matter damage. To this end, items significantly correlated with $\mathrm{mF}$ were included as independent variables and $\mathrm{mF}$ was defined as the dependent variable. The level of significance was set at $\mathrm{p}<0.05$. The IBM Statistical Package for the Social Sciences (SPSS) v. 25 was used for data analyses.

\section{RESULTS}

In this study, 82 older adults were included (mean age $=72.97 \pm 8.84$ years, range $=60-91$ years; education $=5.50 \pm 3.54$ years, range $=0-16$ years; $54.9 \%$ female participants). Concerning diagnoses, 41 patients were classified as presenting AD and 41 had VaD. Prevalence of NPS in the whole sample was $90.8 \%$ of participants.

$\mathrm{AD}$ subjects were significantly older than $\mathrm{VaD}$ patients $(p<0.001)$. No differences between groups were found for education or global cognitive performance (CAMCOG scores). However, subjects with $A D$ performed significantly better on the CLOX 1 and 2 than $\mathrm{VaD}$ subjects $(\mathrm{p}<0.001)$. The $\mathrm{VaD}$ cluster scored significantly higher on the NPI Apathy item than the $A D$ cluster $(p<0.001)$. None of the other NPS domains significantly distinguished the groups. These findings are shown in Table 1.

As expected, $\mathrm{AD}$ patients had lower scores on the $\mathrm{mF}$ and higher scores on the De Leon scale than $\mathrm{VaD}$

Table 2. Distribution of categorical variables between the diagnostic groups.

\begin{tabular}{|c|c|c|c|c|}
\hline Variables & & AD & VD & p-value \\
\hline \multirow[t]{2}{*}{ Sex } & Male & 16 & 21 & \multirow{2}{*}{ n.s. } \\
\hline & Female & 25 & 20 & \\
\hline \multirow[t]{4}{*}{$\mathrm{mF}$} & 0 & 20 & 2 & \multirow{4}{*}{$<0.001$} \\
\hline & 1 & 21 & 11 & \\
\hline & 2 & 0 & 22 & \\
\hline & 3 & 0 & 6 & \\
\hline \multirow[t]{4}{*}{ Hippocampus } & 0 & 0 & 16 & \multirow{4}{*}{$<0.001$} \\
\hline & 1 & 16 & 20 & \\
\hline & 2 & 18 & 5 & \\
\hline & 3 & 7 & 0 & \\
\hline \multirow[t]{5}{*}{ CDR } & 0 & 0 & 0 & \multirow{5}{*}{ n.s. } \\
\hline & 0.5 & 0 & 0 & \\
\hline & 1 & 27 & 24 & \\
\hline & 2 & 14 & 17 & \\
\hline & 3 & 0 & 0 & \\
\hline
\end{tabular}


Table 3. Sociodemographic, clinical/cognitive and NPI staging score data.

\begin{tabular}{|c|c|c|c|c|c|}
\hline Variables & $\mathrm{mF}=0$ & $\mathrm{mF}=1$ & $\mathrm{mF}=2$ & $\mathrm{mF}=3$ & p-value \\
\hline Age & $73.0 \pm 18.38$ & $65.18 \pm 7.40$ & $70.18 \pm 8.35$ & $73.66 \pm 6.86$ & n.s. ${ }^{*}$ \\
\hline Education & $6.00 \pm 2.82$ & $5.36 \pm 3.38$ & $5.45 \pm 3.44$ & $3.66 \pm 2.94$ & n.s. ${ }^{*}$ \\
\hline Gender (M/F) & $0 / 2$ & $8 / 3$ & $10 / 12$ & $3 / 3$ & n.s. ${ }^{\star *}$ \\
\hline $\operatorname{CDR}(0 / 0.5 / 1 / 2 / 3)$ & $0 / 0 / 1 / 1 / 0$ & $0 / 0 / 7 / 4 / 0$ & $0 / 0 / 14 / 8 / 0$ & $0 / 0 / 2 / 4 / 0$ & n.s. ${ }^{* \star}$ \\
\hline Hippocampus (0/1/2/3) & $1 / 1 / 0 / 0$ & $6 / 4 / 1 / 0$ & $6 / 13 / 3 / 0$ & $3 / 2 / 1 / 0$ & n.s. ** \\
\hline CAMCOG & $65.00 \pm 4.24$ & $57.09 \pm 8.14$ & $57.09 \pm 9.39$ & $52.66 \pm 2.94$ & n.s. ${ }^{*}$ \\
\hline CLOX 1 & $8.50 \pm 0.70$ & $7.90 \pm 1.75$ & $6.77 \pm 1.65$ & $6.00 \pm 0.89$ & n.s. ${ }^{*}$ \\
\hline CLOX 2 & $9.50 \pm 0.70$ & $8.18 \pm 1.99$ & $7.77 \pm 1.57$ & $7.90 \pm 1.64$ & n.s.* \\
\hline Delusion & $0 \pm 0$ & $0.72 \pm 1.61$ & $0.50 \pm 1.05$ & $2.00 \pm 3.34$ & n.s." \\
\hline Hallucination & $0 \pm 0$ & $0.54 \pm 1.29$ & $0.95 \pm 1.70$ & $0.50 \pm 0.83$ & n.s." \\
\hline Agitation & $0 \pm 0$ & $1.45 \pm 3.69$ & $1.50 \pm 2.08$ & $1.16 \pm 1.83$ & n.s. ${ }^{*}$ \\
\hline Depression & $3.00 \pm 4.24$ & $2.27 \pm 3.22$ & $2.36 \pm 3.04$ & $5.50 \pm 4.80$ & n.s. ${ }^{*}$ \\
\hline Anxiety & $0 \pm 0$ & $1.36 \pm 3.10$ & $0.72 \pm 1.45$ & $2.00 \pm 4.89$ & n.s. ${ }^{\#}$ \\
\hline Euphoria & $0 \pm 0$ & $0 \pm 0$ & $0.90 \pm 0.42$ & $0 \pm 0$ & n.s. ${ }^{\#}$ \\
\hline Apathy & $0 \pm 0$ & $4.27 \pm 3.28$ & $4.68 \pm 3.09$ & $8.00 \pm 4.17$ & $\mathrm{mF}=0 \neq m F=3^{\star}$ \\
\hline Disinhibition & $0 \pm 0$ & $0.18 \pm 0.60$ & $0.09 \pm 0.42$ & $1.16 \pm 1.60$ & $\mathrm{mF}=2 \neq \mathrm{mF}=3^{\#}$ \\
\hline Irritability & $0 \pm 0$ & $1.63 \pm 3.88$ & $1.04 \pm 2.19$ & $0.66 \pm 1.63$ & n.s. ${ }^{\#}$ \\
\hline Motor & $0 \pm 0$ & $0 \pm 0$ & $0.54 \pm 2.55$ & $1.33 \pm 3.26$ & n.s." \\
\hline Sleep & $0 \pm 0$ & $0.90 \pm 2.07$ & $1.09 \pm 2.36$ & $1.66 \pm 3.20$ & n.s." \\
\hline Appetite Change & $0 \pm 0$ & $0.36 \pm 1.20$ & $1.27 \pm 2.84$ & $0.66 \pm 1.23$ & n.s. ${ }^{\#}$ \\
\hline NPI total & $3.00 \pm 4.24$ & $13.36 \pm 15.40$ & $14.86 \pm 10.50$ & $24.66 \pm 16.88$ & n.s. ${ }^{*}$ \\
\hline
\end{tabular}

*ANOVA and Tukey's post-hoc; **Pearson's Chi-square; "Kruskal-Wallis.

subjects, as shown in Table 2. CDR scores did not differ between groups.

When the sample was clustered according to $\mathrm{mF}$ scores, the group with no white-matter hyperintensities $(\mathrm{mF}=0)$ differed significantly on the NPI Apathy subtest compared to those with severe white-matter impairments. Disinhibition score was higher in subjects with $\mathrm{mF}=3$ than in those with moderate white-matter hyperintensities $(\mathrm{mF}=2)$. No cognitive or other behavioral variables distinguished $\mathrm{mF}$ groups (Table 3 ).

After controlling for scores on the De Leon scale, performance on the CLOX 1, Apathy and Disinhibition moderately correlated with $\mathrm{mF}$ (Table 4 ). These variables were included in the Linear regression Model, using $\mathrm{mF}$ as the dependent variable. Apathy and CLOX 1 were predictors of severity of vascular burden.

\section{DISCUSSION}

The present study indicated that NPS are present in over $90 \%$ of subjects with dementia, a rate in line with previous reports. ${ }^{6,14,15}$ Of the NPS domains, apathy
Table 4. Correlations between $\mathrm{mF}$ and behavioral and cognitive variables, after controlling for degree of hippocampal atrophy.

\begin{tabular}{lcc}
\hline Variable & Correlation $\mathrm{mF}$ & $\mathrm{p}$-value \\
\hline CAMCOG & n.s. & - \\
\hline CLOX 1 & $-0.41^{*}$ & $\mathrm{p}<0.01$ \\
\hline CLOX 2 & n.s. & - \\
\hline Delusions & n.s. & - \\
\hline Hallucinations & n.s. & - \\
\hline Agitation & n.s. & - \\
\hline Depression & n.s. & - \\
\hline Anxiety & n.s. & - \\
\hline Euphoria & n.s. & p<0.05 \\
\hline Apathy & $0.40^{*}$ & $\mathrm{p}<0.05$ \\
\hline Disinhibition & $0.32^{\star *}$ & - \\
\hline Irritability & n.s. & - \\
\hline Motor & n.s. & - \\
\hline Sleep & n.s. & - \\
\hline Appetite Change & n.s. & - \\
\hline NPI total & n.s. & - \\
\hline
\end{tabular}

aPearson's Partial correlation; 'Spearman's Partial Correlation. 
appeared to be strongly correlated with the diagnosis of $\mathrm{VaD}$ and might reflect higher severity of subcortical vascular damage. Our data also supports the idea that performance on the CLOX 1 , a measure of executive control, ${ }^{24}$ may reflect degree of vascular burden.

Integrity of frontal and subcortical interconnections has been deemed crucial for executive function, as assessed by the CLOX $1 .{ }^{28}$ In fact, this task may identify subcortical impairment even in early stages, according to a previous study, which might be explained by the complexity of this cognitive function, in terms of the brain regions potentially recruited during executive tasks. ${ }^{29}$ For instance, the ability to draw a clock without visual stimuli might be dependent on the coordinated activation of visuospatial, memory and motor controlrelated cortices, as well as of prefrontal areas responsible for planning, abstract thinking and working memory. ${ }^{30}$ It could be inferred that vascular-related disconnection of one or more of these long subcortical inter-lobe fibers, which allow this combined activity of brain areas, may affect executive function. ${ }^{31}$

Previous reports describe a higher prevalence of apathy in $\mathrm{VaD}$ compared to AD. ${ }^{32-35}$ This symptom could be described as loss of initiative and motivation. ${ }^{21}$ Akin to executive function, apathy might stem from disconnections of frontal-subcortical regions. Consistently, studies have shown that damage to the uncinate fasciculus can lead to loss of interconnections among prefrontal areas, amygdala and the fusiform gyrus, which could result in the onset of apathy. ${ }^{36-38}$ Moreover, cholinergic pathways, which are spread widely throughout the subcortex, may also be disrupted in small vessels disease. ${ }^{32,33}$ Evidence has suggested a role of those circuits for motivational drive; ${ }^{39}$ therefore, lesions to the cholinergic system may also result in apathy.

Disinhibition is classified as impulsive hypersexualized behavior, activities or comments, with an excess of jocosity and even weird or inappropriate behavior. The presence of this clinical feature also distinguished $\mathrm{AD}$ from $\mathrm{VaD}$ in our sample; however, mean scores on this NPI domain were low, implying that these symptoms were not prominent in our sample. Difficulties in social cognition and inhibitory control, which are also related to the prefrontal cortex, were associated with this finding in some studies. ${ }^{40}$
The results of this study highlight the importance of vascular load in the severity of apathy and disinhibition. Similar data were found in previous studies investigating apathy in $\mathrm{VaD},{ }^{32,33}$ but are not reported in studies related to $\mathrm{VaD}$ and disinhibition. The evidence in the present study may point to a possible influence of whitematter hyperintensities on the genesis of disinhibition. Therefore, better control of cardiovascular risk factors is of paramount importance for health in late-life.

Some limitations of this study should be highlighted. Significant age differences were evident between AD and $\mathrm{VaD}$ patients. However, this finding, which might be interpreted as a potential confounding factor regarding cognitive and neuroimaging variables, could correspond to some aspects of these disorders in real life. Neurodegenerative diseases may be more prevalent in advanced age groups, ${ }^{1}$ whereas $\mathrm{VaD}$, at least the "pure" presentations, might be more prevalent in younger subjects. ${ }^{41,42}$ Hence, the attempts to control for or match age between groups could have impacted the ecological validity of our findings. Moreover, the cross-sectional design of the study precluded further inferences, especially regarding prevalence of NPS. In addition, it has been recognized that most subjects with dementia may present both $\mathrm{AD}$ and $\mathrm{VaD}$ pathology in the brain, which cannot be detected using MRI and may affect the ability to draw conclusions when comparing groups. Finally, as observed in most informant-based instruments, the NPI may have inherent biases. Cultural issues and the presence of caregiver burden, or even the neuropsychiatric symptom itself, may affect answers on the instrument. Therefore, responses might exhibit underestimation or overestimation of the true situation. ${ }^{10,12}$

In conclusion, the authors suggest that measures of apathy and executive function, namely the CLOX, can accurately distinguish $\mathrm{VaD}$ from $\mathrm{AD}$. A possible role of frontal-subcortical disconnection could be relevant to both phenomena.

Author contributions. Study design: Chan Tiel, Ana Beatriz Calmon. Data analysis: Felipe Kenji Sudo. Intellectual contribution to writing of manuscript: Chan Tiel, Felipe Kenji Sudo, Ana Beatriz Calmon. Statistics and Tables: Felipe Kenji Sudo. Writing of manuscript: Chan Tiel, Felipe Kenji Sudo. Final revision: Ana Beatriz Calmon.

\section{REFERENCES}

1. Feldman $\mathrm{H}$, Kertesz A. Diagnosis, classification and natural history of degenerative dementias. Can J Neurol Sci 2001;28(Suppl 1):S17-27.

2. LoGiudice D, Watson R. Dementia in older people: an update. Intern Med J 2014;44:1066-73.
3. Lyketsos CG, Steinberg M, Tschanz JT, Norton MC, Steffens DC, Breitner JC. Mental and behavioral disturbances in dementia: findings from the cache county study on memory in aging. Am J Psychiatr 2000; 157(5):708-14 
4. Aalten P, Verhey FR, Boziki M, Bullock R, Byrne EJ, Camus V, et al. Neuropsychiatric syndromes in dementia. Results from the European Alzheimer disease consortium: part I. Dement Geriatr Cogn Disord 2007;24(6):457-63.

5. Caputo M, Monastero R, Mariani E, Santucci A, Mangialasche F, Camarda R, et al. Neuropsychiatric syptoms in 921 elderly subjects with dementia: a comparison between vascular and neurodegenerative types. Acta Psychiatr Scand 2008;117:455-64.

6. Hsieh CJ, Chang CC, Lin CC. Neuropsychiatric profiles of patients with Alzheimer's disease and vascular dementia in Taiwan. Int J Geriatr Psychiatr 2009;6:570-7.

7. D'Onofrio G, Sancarlo D, Panza F, Copetti M, Cascavilla L, Paris F, et al Neuropsychiatric symptoms and functional status in Alzheier's disease and vascular dementia patients. Curr Alzheimer Res 2012;9(6):759-71.

8. Mega MS, Cummings JL, Fiorello, Gornbein J. The spectrum of behavioral changes in Alzheimer's disease. Neurology 1996;46(1):130-5.

9. Lyketsos CG, Carrilo MC, Ryan JM, Khachaturian AS, Trzepacz P, Amatniek J, et al. Neuropsychiatric symptoms in Alzheimer's disease. Alzheimers Dement. 2011;7(5):532-9.

10. Cerejeira J, Lagarto L, Mukaetova-Ladiska EB. Behavioral and psychological symptoms of dementia. Front in Neurol 2012;3:1-21.

11. Stella F, Radanovic M, Balthazar ML, Canineu PR, de Souza LC, Forlenza OV. Neuropsychiatric symptoms in the prodromal stages of dementia. Curr Opin Psychiatry 2014;27(3):230-5.

12. Geda YE, Schneider LS, Gitlin LN, Miller DS, Smith GS, Bell Jm, et al Neuropsychiatric symptoms in Alzheimer's disease: past progress and anticipation of the future. Alzheimers Dement 2013;9(5):602-8.

13. Frisoni B, Rozzini L, Gozetti, et al. Behavioral syndromes in Alzheimer's disease: description and correlates. Dement Geriatr Cogn Disord 1999; 10:130-8

14. Fuh JL, Wang SJ, Cummings JL. Neuropsychiatric profiles in patients with Alzheimer's disease and vascular dementia. J Neurol Neurosurg Psychiatr 2005;76:1337-41.

15. Fernández-Martínez M, Castro J, Molano A, Zarranz J, Rodrigo R, Ortega R. Prevalence of neuropsychiatric symptoms in Alzheimer's disease and vascular dementia. Curr Alzheimer Res 2008:5:61-69.

16. Perri R, Monaco M, Fadda L, Caltagirone C, Carlesimo GA. Neropsychological correlates of behavioral symptoms in Alzheimer's disease, fronta variant of frontotemporal, subcortical vascular, and lewy body dementias: a comparative study. J Alzheimers Dis 2014;39(3):669-77.

17. Seildl JNT. Cognitive correlates of neuropsychiatric syndromes measured over time in patients with Alzheimer's disease. July, 2014, University of Houston. http://hdl.handle.net/10657/1117

18. Lyketsos CG, Lopez O, Jones B, Fitzpatrick AL, Breitner J, DeKosky S. Prevalence of neuropsychiatric symptoms in dementia and mild cognitive impairment: result from the cardiovascular health study. JAMA 2002:288:1475-83

19. Cummings JL, Mega M, Gray K, Rosemberg-Thompson S, Carusi DA, Gornbein J. The neuropsychiatric inventory: comprehensive assessment of psychopathology in dementia. Neurology 1994;44: 2308-14

20. Zhao QF, Tan L, Wang HF, Jiang T, Tan MS, Tan L, et al. The prevalence of neuropsychiatric symptoms in Alzheimer's disease: Systematic review and meta-analysis. J Affect Disord 2016;190:264-71.

21. Camozzato A, Kochhann R, Simeoni C, Konrath CA, Pedro Franz A Carvalho A, et al. Reliability of the Brazilian Portuguese version of the Neuropsychiatric Inventory (NPI) for patients with Alzheimer's disease and their caregivers. Int Psychogeriatr 2008;20:383-93.

22. Brucki SM, Nitrini R, Caramelli P, Bertolucci PH, Okamoto IH. Suggestions for utilization of the mini-mental state examination in Brazil. Arc Neuropsiquiatr 2003;61(3B):777-81.

23. Roth M, Tym E, Mountjoy CQ, Huppert FA, Hendrie H, Verma S, et al.
CAMDEX. A standardised instrument for the diagnosis of mental disorder in the elderly with special reference to the early detection of dementia. Br J Psychiatry 1986;149:698-709.

24. Royall DR, Cordes JA, Polk M. CLOX: an executive clock drawing task. J Neurol Neurosurg Psychiatry 1998;64:588-94.

25. Morris JC, Ernesto C, Schafer K, Coats M, Leon S, Sano M, et al. Clinical dementia rating training and reliability in multicenter studies: the studies: the Alzheimer's Disease Cooperative Study experience. Neurology 1997:48(6):1508-10.

26. Pantoni L, Basile AM, Pracucci G, Asplund K, Bogousslavsky J, Chabriat $\mathrm{H}$, et al. Impact of ag-related cerebral white matter changes on the transition to disability - the LADIS study: rationale, design and methodology. Neuroepidemiology 2005;24(1-2):51-62.

27. de Leon MJ, Golomb J, George AE, Convit A, Tarshish CY, McRae T, et al. The radiologic prediction of Alzheimer's disease: the atrophic hippocampal formation. Am J Neuroradiol 1993;14(4):897-906.

28. Royall DR, Lauterbach EC, Cummings JL, Reeve A, Rummans TA, Kaufer DI, et al. Executive control funtion: a review of its primise and challenges for clinical research. A report from the Committee on Research of the American Neuropsychiatric Association. J Neuropsychiatry Clin Neurosci 2002;14(4):377-405.

29. Sudo FK, Alves GS, Tiel C, Ericeira-Valente L, Moreira DM, Laks J, et al. Neuroimaging criteria and cognitive performance in vascular mild cognitive impairment: A systematic review. Dement Neuropsychol 2015;9(4):394-404.

30. Ino T, Asada T, Ito J, Kimura T, Fukuyama H. Parieto-frontal networks for clock drawing revealed with fMRI. Neurosci Res 2003;45(1):71-7.

31. Sudo FK, Amado P, Alves GS, Laks J, Engelhardt E. A continuum of executive function deficits in early subcortical vascular cognitive impairment: A systematic review and meta-analysis. Dement Neuropsychol 2017:11(4):371-80.

32. Chin J, Seo SW, Kim SH, Park A, Ahn HJ, Lee BH, et al. Neurobehavioral dysfunction in patients with subcortical vascular mild cognitive impairment and subcortical vascular dementia. Clin Neuropsychol 2012;26(2):224-38.

33. Gupta M, Dasgupta A, Khwaja GA, Chowdhury D, Patidar Y, Batra A. Behavioural and psychological symptoms in poststroke vascular cognitive impairment. Behav Neurol 2014;2014:430128.

34. Jin Y-L, Zhang H, Gao YZ, Shu M, Xu Y, Liu X, et al. Neuropsychiatric symptoms in patients with vascular dementia in mainland China. Transl Neurosci 2015;6(1):157-61.

35. Anor CJ, O'Connor S, Saund A, Tang-Wai DF, Keren R, Tartaglia MC. Neuropsychiatric symptoms in Alzheimer disease, vascular dementia, and mixed dementia. Neurodegener Dis 2017;17(4-5):127-34.

36. Tekin S, Cummings JL. Frontal-subcortical neuronal circuits and clinical neuropsychiatry: an update. J Psychosom Res 2002;53:647-54

37. Boublay N, Schott AM, Krolak-Salmon P. Neuroimaging correlates of neuropsychiatric symptoms in Alzheimer's disease: a review of 20 years of research. Euro J Neurol. 2016;23:1500-9.

38. Zhao H, Tang W, Xu X, Zhao Z, Huang L. Functional magnetic resonance imaging study of apathy in Alzheimer's disease. J Neuropsychiatry Clin Neurosci 2014;26(2):136-41.

39. Martinowich K, Cardinale KM, Schloesser RJ, Hsu M, Greig NH, Manji HK. Acetylcholinesterase inhibition ameliorates deficits in motional drive. Behav Brain Funct 2012;8:15.

40. Béreau M. Hipersexuality in Neurological disorders: from disinhibition to impulsivity. Front Neurol Neurosci. 2018;41:71-6.

41. Román GC. Vascular dementia may be the most common form of dementia in the elderly. J Neurol Sci 2002;203-204:7-10.

42. Attems J, Jellinger KA. The overlap between vascular disease and Alzheimer's disease - Lessons from pathology. BMC Med 2014;12:206. 